\title{
A Dynamic Information-Based Parking Guidance for Megacities considering Both Public and Private Parking
}

\author{
Jong-Ho Shin, ${ }^{1}$ Namhun Kim, ${ }^{2}$ Hong-bae Jun, ${ }^{3}$ and Duck Young Kim ${ }^{2}$ \\ ${ }^{1}$ Department of Industrial Engineering, Chosun University, Gwangju, Republic of Korea \\ ${ }^{2}$ Department of Human \& Systems Engineering, Ulsan National Institute of Science and Technology, Ulsan, Republic of Korea \\ ${ }^{3}$ Department of Industrial Engineering, Hongik University, Seoul, Republic of Korea \\ Correspondence should be addressed to Duck Young Kim; dykim@unist.ac.kr
}

Received 24 January 2017; Revised 20 April 2017; Accepted 6 June 2017; Published 18 July 2017

Academic Editor: Luigi Dell'Olio

Copyright (C) 2017 Jong-Ho Shin et al. This is an open access article distributed under the Creative Commons Attribution License, which permits unrestricted use, distribution, and reproduction in any medium, provided the original work is properly cited.

\begin{abstract}
The constantly increasing number of cars in the megacities is causing severe parking problems. To resolve this problem, many cities adopt parking guidance system as a part of intelligent transportation system (ITS). However, the current parking guidance system stays in its infant stage since the obtainable information is limited. To enhance parking management in the megacity and to provide better parking guidance to drivers, this study introduces an intelligent parking guidance system and proposes a new methodology to operate it. The introduced system considers both public parking and private parking so that it is designed to maximize the use of spatial resources of the city. The proposed methodology is based on the dynamic information related parking in the city and suggests the best parking space to each driver. To do this, two kinds of utility functions which assess parking spaces are developed. Using the proposed methodology, different types of parking management policies are tested through the simulation. According to the experimental test, it is shown that the centrally managed parking guidance can give better results than individually preferred parking guidance. The simulation test proves that both a driver's benefits and parking management of a city from various points of view can be improved by using the proposed methodology.
\end{abstract}

\section{Introduction}

While automotive transportation (hereafter called "car") is of vital importance in everyday urban life, the constantly increasing number of cars has, however, become a messy problem in big cities. In particular, the parking problem has been considered as one of the most urgent issues to be solved, since it is hard to meet the rapidly growing parking demands with the limited parking resources within a city. It is not unusual to see many cars circling around parking facilities hunting for an available parking space, which causes severe energy losses, environmental pollution, and other irritating problems. Since the high cost of spatial resources limits the construction of new public parking in a city, increasing the parking supply has not been always a good solution for the parking problems. Therefore, over the past few decades, several parking management systems and policies have been proposed and implemented as alternative solutions in many big cities.

To solve the parking problem, many cities are already utilizing intelligent transportation systems (ITS) that include parking management functions for efficient transportation management. However, the parking management functions in the current version of ITS are still in their infancy. Recent advances in information and communication technologies (ICT) such as overhead sensors, wire/wireless networks, and smart phones have made it possible to provide very useful parking information to drivers. For example, modern parking buildings equipped with parking spot monitoring sensors that are already purchasable from the market are assisting drivers to find vacant parking spots within the buildings. Widening our lens to the parking management throughout an entire city, parking guidance information systems (PGIS) characterized by variable message sign (VMS) are frequently 
deployed in major cities. The current VMS provides drivers with only brief information, such as the number of vacant parking spots and the distance and the direction to parking facilities. Based on this information and driver's experience (i.e., prior knowledge), drivers should decide the best parking facility by himself/herself. However, this decision is vague and erratic, since there is no clear way of rank-ordering the parking facilities to find the best one with respect to multiple decision criteria, such as the current number of available parking spots, parking cost, distance, or traffic conditions. Furthermore, the direction guidance provided by the current VMS is too imprecise to find a parking facility easily. These limitations must be taken into account when developing a new intelligent parking guidance system, so that it helps the drivers' decision-making by providing dynamic routing guidance obtained by considering both the driver's preference in selecting parking and real-time parking data.

From the perspective of parking supply, a policy called parking sharing has been introduced to maximize the utilization of the existing parking resources by using private parking spaces within a city. In big cities, there are many private parking spaces which are unused by owners during specific time periods. If other drivers are allowed to use these unoccupied private parking spaces, the shortage of parking spaces can be relieved. To connect the owners of private parking spaces with drivers, some cities are operating parking sharing programs. Mostly, the parking sharing is done by a contract between the owner of the private parking and the driver who needs the parking space regularly. However, parking sharing according to the scheduled plan by contract sometimes fails to instantly respond to the dynamic parking demand within a city. In this sense, an integrated information service of private parking spaces and public ones will help drivers in finding better parking places. In other words, the extension of parking management to the private parking as well as public parking can increase the available parking resources of a city without additional cost regarding construction, so that the utilization of the spatial resource can be improved. To do this, it is indispensable to develop and integrate various ICT, such as parking spot monitoring sensors, communication networks to transfer monitored data, management systems for real-time updates of the availability of parking spots, effective algorithm to provide the best parking spot to drivers, and a personal navigation device to guide a driver to the designated parking. Among these, in this paper, the authors aim to present an overview of system architecture to operate an intelligent parking guidance program, highlighting a new methodology to provide information of the best parking spot available to drivers based on the collective real-time parking status, including both public and private parking.

The rest of this paper is organized as follows. The second section describes the advantages and shortcomings of existing parking guidance models. Recent advances in ICT for a parking management system are also introduced in this section. Section 3 presents the overall system architecture that underpins the proposed parking guidance methodology, while the detailed description of the main algorithm and newly defined functions to search, assess, compare, and determine the best parking space is made in Section 4 .
Simulation-based validation has been conducted to evaluate the proposed methodology, and its results are discussed in Section 5. The conclusion and future works are summarized in the last section.

\section{State of the Art}

2.1. Sensor Network for Intelligent Parking Guidance. For the intelligent parking guidance, it is necessary to collect and use dynamic parking information, such as currently available vacant parking spots, parking fees, and parking usage history. Recently developed ICT makes it possible to monitor parking in real-time and remotely transfer parking status to a parking management system. To do this, two kinds of technical support are crucial: (1) monitoring sensors and (2) communication networks. To check parking status, different types of sensors are developed and implemented. The most used types of monitoring sensors are ultrasonic, magnetic, and video camera. Some of the studies propose a single type sensor system, which adopts one of these three sensors to implement the intelligent parking system [1-4], while some introduce a combined sensor system with heterogeneous input signals [5-8]. From the previous works, different types of sensors are applied to monitor the availability of parking according to the working environment, accuracy, and cost. Depending on the objective and operational algorithm of a parking guidance system, it is important to choose the most appropriate type of sensor with the consideration of data modality.

Another research interest has been building sensor network to transfer sensing data. For the communication of sensor data, both wire and wireless solutions are considered and implemented. Shin et al. [9] selected ZigBee as a communication protocol due to its low cost of installation. Boda et al. [10] implemented specially developed wireless sensor nodes (mica2) which were manufactured by Crossbow Technologies. Srikanth et al. [11] applied RF communication into the sensor network in transferring sensor data. Silva et al. [12] implemented a wireless network based on the IEEE 802.15.4 standard. Caliskan et al. [13] introduced a vehicular ad hoc network (VANET) which was used to transfer the status information of a parking lot through cars and proposed an application of VANETs into parking data transmission.

Different kinds of communication protocols are considered in the previous works, and wireless solutions are mostly preferred due to their low installation cost. Considering the previous research works regarding sensors and sensor networks, an intelligent parking guidance system using ubiquitous environment to monitor and control parking is quite tangible and applicable. In reality, however, the current application of collected data through these technologies is quite limited. Most of the applications are restricted to the management of a single parking facility. Few of them consider parking management from the perspective of a city. To extend parking management from a single parking facility to multiple parking facilities and private parking within a city, the reliability of sensors in an outdoor environment should be improved, and long-range communication should be considered in the sensor network. 
2.2. Parking Guidance for a City. Even though the technical developments to monitor and communicate parking data are well established, their applications into parking management throughout a city are still immature. Most installed parking guidance information systems (PGIS) in many cities have a form of message board which is called a variable message sign (VMS). The main research issue regarding the operation of VMS is to enhance the information quality of the parking lot's availability, such as information updating intervals and the expected number of available parking spaces. Mei and Tian [14] studied the available parking spaces on VMS to be presented to drivers in periods of high demand. A new parking guidance information configuration model based on parking choice behavior was proposed, and the optimized configuration of VMS to get the shortest total vehicle kilometers of travel was calculated using a mathematical program. Thompson et al. [15] also studied the best car park availability information. In their work, the influence of parking information from PGI signs on the overall performance of the traffic system was estimated using a behavioral model [16] of parking choice. Their study proved that the driving distance of an automobile could be reduced by the optimized configuration of PGI display intervals, which showed a possibility of relieve the parking problem by providing better parking information. Caicedo [17] studied the effect of parking information given by a VMS. A demand assignment model to evaluate the benefits of manipulating the information on a VMS was developed and tested in this research.

Various researchers are interested in the enhancement of VMS configuration to provide better parking information. However, in spite of the usefulness of PGIS based on VMS, the effect on the system-wide reduction in travel time throughout a city and vehicle benefit may seem to be relatively small $[18,19]$. The parking guidance relying on VMS has several drawbacks: (1) drivers may not find near vacant parking spots by merely following the VMS, (2) drivers may miss a better parking spot while heading to a specific parking spot, due to the temporal discrepancy, (3) parking resource utilization becomes imbalanced, and (4) parking guidance itself causes new traffic congestion. The provided information by VMS becomes outdated during driving, since it cannot respond dynamically to the information update. Moreover, considering the characteristics of VMS, the deliverable information is limited

To overcome these limitations, an advanced parking guidance system that can provide intelligent parking information is required. To extend deliverable parking information and enhance parking management of a city, Chou et al. [20] proposed a parking management system based on an agentbased platform. The proposed system used an intelligent agent system, which helps a driver to negotiate parking prices with car parks so that the driver can find better and cheaper parking. For this propose, the authors showed a possibility of extending the function of PGIS by adding a negotiation process between the parking facility and the driver based on the parking fee. Teodorović and Lučić [18] adopted a reservation concept combined with parking revenue management system. The reservation system was designed to maximize the revenue of a parking facility, so the parking request from a driver could be accepted or rejected as decided by the facility. Unlike Chou et al's work, their system focused more on the operation perspective of a parking facility. Srikanth et al. [11] also proposed a reservation function through the Internet or GSM (Global System for Mobile Communications) for the convenience of the driver. Within the proposed system, a driver could reserve a parking spot remotely through a client application. The reservation could secure a parking spot until the driver arrives. However, these systems may not be suitable for helping the driver's decision-making for finding the best parking space.

To help the decision of the optimal parking selection, Caliskan et al. [13] proposed an estimation method of future parking lot occupancy using the information collected from the developed vehicular ad hoc networks (VANETs). Since the delivered information of parking lot status through VANETs can be outdated when a driver arrives at the parking lot, it is necessary to predict occupancy in advance. An occupancy prediction based on the Markov model was proposed in their work. By these works, more intelligent information supporting finding parking spaces was studied and introduced for enhanced parking management throughout a city.

In a similar vein, some research works have been interested in the behavior of the driver in parking selection. The choice of parking is closely related to parking guidance, so many researchers tried to make a model to explain parking selection. For example, Bonsall and Palmer [21] studied parking choice behavior using a travel choice simulator. Jonkers et al. [22] also showed driver behavior in searching for parking places. Mei et al. [23] explained the parking searching process and related factors in parking choices. As an advanced system to provide intelligent parking guidance, new parking management systems have been introduced by several researchers. Giuffrè et al. [24] proposed an advanced parking guidance system as a conceptual architecture of an IPA (Intelligent Parking Assistant) aiming at overcoming current parking management solutions for smart cities. Jonkers et al. [22] introduced an intelligent parking service (IPS) which was connected with PGIS. Using the IPS, drivers could be assisted with navigation, reservation, and payment. As a driver approaches a destination, he/she is advised of an available parking place which can be reserved. Moreover, the payment is automatically handled by the IPS.

E-parking, as an innovative platform which allows drivers to obtain parking information before or during a trip and to reserve a parking spot, was proposed and evaluated in the study by Rodier and Shaheen [25] for the evaluation of the impact of smart parking systems. Geng and Cassandras [26] proposed a smart parking system designed for an urban environment. The proposed system performed a smart allocation between drivers and parking and provided a reservation function. The best parking was suggested considering proximity to the destination, parking cost, and overall parking capacity. In their work, the central server assigns a proper parking spot to each driver and the driver could decide to accept the reservation. If the driver is not satisfied with the suggested parking, he/she should wait until the next 
assignment. The parking guidance by this system is based on reservations, so there is lack of consideration of drivers who do not want to use reservation. The system proposed by Geng and Cassandras is similar to the developing system in this paper in that the decision support of the parking selection and reservation function is implemented in the parking guidance system. However, the considering factors in finding the best parking are limited, and the guidance based on reservation confines drivers' preference, so there is still the need to improve parking guidance system intelligently.

As the recent application of an intelligent parking management system in the field, San Francisco, USA, built a new system called the SFpark Pilot Program in order to help drivers who are seeking a parking space. Under this program, drivers can check available parking spaces around them through the Internet. However, this application shows its early stage of intelligent parking guidance system so that the decision support to find the best parking is still missing.

Considering previous efforts to improve parking management, the available providing information becomes diverse, and some developing systems try to adopt new functions to increase driver's convenience. However, most of them are lacking decision support in the selection of the best parking space, considering various factors related parking choice. Only a few consider user preference in the selection and suggestion of the best parking place. None of them considers private parking in the parking management of a city. Moreover, the parking guidance in real-time environment is still regarded as a challenging issue due to the large amount of data processing.

\section{System Architecture}

3.1. Overall System Architecture. The intelligent parking guidance system presented in this paper is composed of diverse IT components, such as advanced sensors to monitor parking spot occupancy, wire/wireless communication to transfer parking data, a central server to manage and generate parking information for the whole city, and personal navigation devices to handle the parking requests and guide the drivers. The overall system architecture and the role of each component are depicted in Figure 1. The detailed constitution of the developing system will be omitted in this paper since the focus here is to propose the methodology framework of a system at the operational level and to verify the model in providing a driver with the best parking spot in a real-time manner.

Unlike the existing parking management systems, the presented system is designed to include private parking in the parking management of a city, as well as public parking facilities. To do this, the data of private parking should be also traced by the central server. The status of private parking is monitored by a sensor installed at the request of the owner. The available parking time and expecting parking cost are registered to the central server by the owner through the provided web interface. Whenever the availability schedule of private parking is changed, the owner can update it to the central server. The registered private parking is considered as a candidate of available parking spots in the parking selection, along with public parking. By providing private parking, the owner can have monetary benefits, and the city can extend parking resources without any further construction costs and investment.

3.2. Data Flow of Intelligent Parking Guidance System. Under the introduced system architecture (refer to Figure 1) in Section 3.1, various kinds of data are collected and manipulated in order to generate the best parking guidance information. The two main streams of data are from parking spot monitoring sensors and personal navigation devices. The parking spot monitoring sensor checks the parking spot status in real time and transfers it to the central server. The central sever collects all parking spot status data throughout a city and stores it in the equipped database. Some statistical data regarding parking spot occupancy are generated by the central server using historical data and used in the parking selection by the personal navigation device. On the other hand, the personal navigation device handles locational data of the car using the installed map data and GPS. The most important part that assesses and selects the parking spot is also processed by the personal navigation device. The detailed process and related data flow are depicted in Figure 2 using the data flow diagram [27].

According to Figure 2, the parking guidance is triggered by a driver through the personal navigation device. To request parking guidance, the driver should input the destination and preference level of decision factors that will be used in the assessment and selection of the best parking. As soon as parking guidance is requested, the personal navigation device sends the driver's destination and expected parking duration to the central server. The central server finds available parking spots, including both public and private parking, near the destination. Then, the parking and related data (e.g., cost and current occupancy status) are transmitted from the central server to the personal navigation device. A software module in the personal navigation device assesses parking spots and selects the best one with a reservation option as the first step. The driver can decide whether he/she will use the reservation option or not. In the case that the driver accepts the reservation option, the personal navigation device sends a reservation request to the central server so that the provided parking spot is reserved until the driver arrives. Otherwise, the software module reassesses parking spots with different decision factors which are designed to suggest the best parking spot without reservation option. Unlike the evaluation for a reservation, in this parking selection, the uncertainty of finding a vacancy when the driver arrives at the suggested parking spot is considered.

\section{Parking Guidance Methodology}

An important part of the intelligent parking guidance system from the operation viewpoint is the development and validation of a method to find the best parking spot considering both the driver's preference and the public benefit for the city. Geng and Cassandras [26] defined a user's objective function that combines the proximity to the destination with the parking cost, while also ensuring that the overall parking 


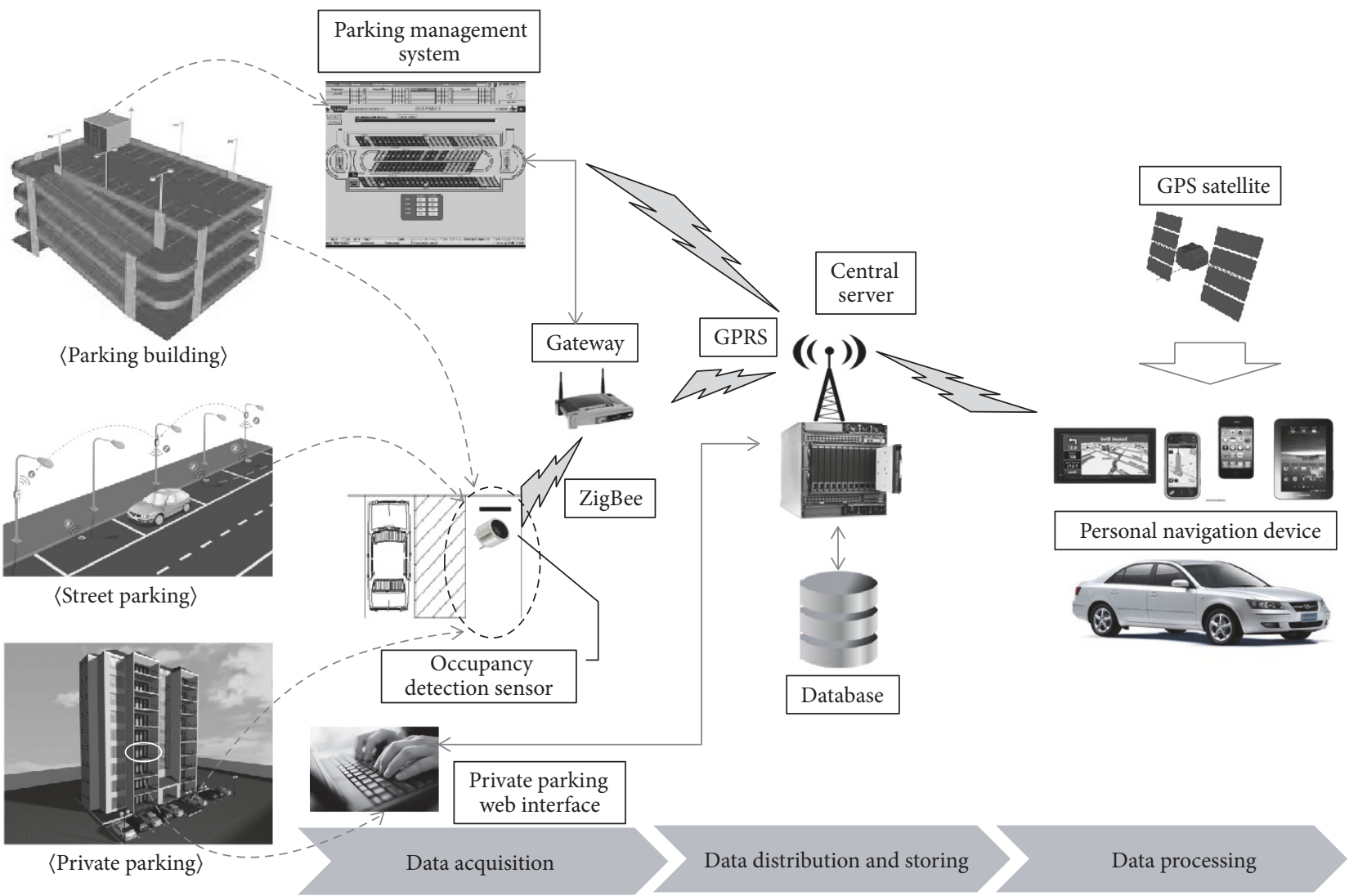

FIGURE 1: Overall system architecture of the proposed intelligent parking guidance system.

capacity is efficiently utilized. The proposed method in this paper is based on this concept, which uses the parking choice model to assess and compare parking spots. This will be explained in the following subsections.

4.1. Parking Choice Model. According to the previous studies on finding the best parking $[16,23,24]$, parking choice can be made by the utility comparison among parking. Therefore, the utility of parking is represented as a generalized cost function that consists of several factors affecting the behavior of parking selection. Various works [28-31] mentioned the factors related to parking behavior such as walking distance to destination, driving and waiting time, parking cost, and service level of parking, safety, and optimal traffic flow. Some of them are chosen from the previous works and some factors are newly defined in the proposed utility function. In this paper, the utility function is also adopted as a decisionmaking criterion in the assessment and selection of parking. Two kinds of utility function, called the utility function for reservation and the utility function for suggestion, are proposed, which are defined in authors' previous work [32], and modified in order to be suitable for a megacity environment. Since the reservation causes additional costs to keep a parking spot vacant, time related factors are included in the first utility function. On the other hand, the second utility function focuses on the possibility of finding a vacant parking spot when the driver arrives at the guided parking. Common factors (i.e., parking cost and traffic congestion) affecting parking selection are included in both utility functions. Since drivers have different preferences in parking choice, the importance of considered factors in the utility function is moderated by the weights on each factor. The parking spots are assessed and compared by the utility function, and the one with the lowest value of utility function is selected. The detailed considering factors and formulations of the utility functions are explained in the following subsections. When the parking guidance is requested, the utilities of available parking spaces are calculated using these two functions so that the parking spaces can be compared and the best parking can be recognized.

4.1.1. Utility Function for Reservation. In crowded urban areas, it is difficult to guarantee that there is a vacant parking when the driver arrives at the guided parking. If the driver fails to find a vacant parking spot when he/she arrives, the driver will have to wander to find another spot, which wastes fuel and time and annoys drivers. To avoid this situation, the real-time reservation option of the proposed system could secure a parking spot until he/she arrives. Since the reservation option requires additional costs to keep the parking spot vacant until the driver arrives, many factors in the utility function are related to time and cost. The driving duration from the current location of the car to the parking spot is important, so this is included in this utility function 


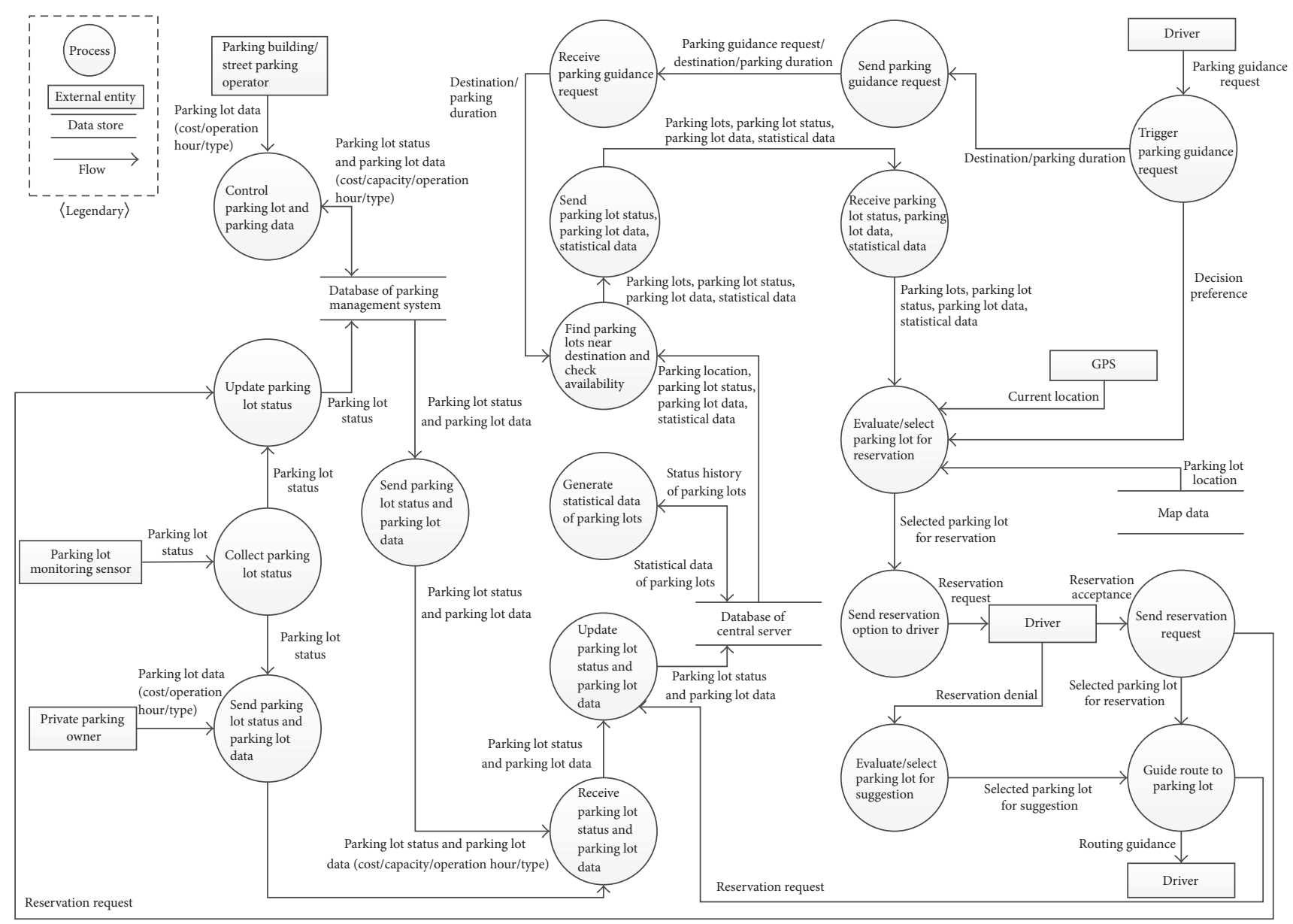

FIgURE 2: Process and data flow of the intelligent parking guidance system.

as one of decision factors. The walking distance from the parking spot to the destination, parking cost, and traffic congestion created by the guidance system itself are also considered as decision factors in parking choice. The defined utility function including all these factors is formulated as

$$
U_{r}\left(T_{d}, D_{w}, P, C\right)=\alpha_{1} T_{d}+\alpha_{2} D_{w}+\alpha_{3} P+\alpha_{4} C,
$$

where

$U_{r}$ is the utility function for reservation,

$T_{d}$ is the driving duration from current location of car to parking spot,

$D_{w}$ is the walking distance from parking spot to destination,

$P$ is the parking cost,

$C$ is the traffic congestion by guidance itself,

$\alpha$ is the weights of each factor.

To calculate the utility, the information of each factor is needed and it comes from the navigation software and the central server. The driving duration, $T_{d}$, is the estimated travel time to arrive at the specified parking from the current location of the requesting car. Since the personal navigation device includes navigation software, the driving distance can be calculated, and the driving duration is estimated by the navigation software. The walking distance can be also calculated in the same way. The information regarding parking cost is stored in the database of the central server and transferred to the personal navigation device when parking guidance is requested. The traffic congestion is defined to avoid parking where too many cars are heading. Hence, the traffic congestion is measured by the number of cars heading to the parking and a high value of traffic congestion prevents the selection of the congested parking spot. When the parking request is sent to the central server, the required information is transmitted to the personal navigation device and the utility of each parking spot is calculated. The lower the value of the utility function the parking has, the higher the priority and chance to be selected.

4.1.2. Utility Function for Suggestion. Unlike the utility function for reservation, this utility function focuses more on the uncertainty that the driver fails to park when he/she arrives at the guided parking. Since the parking suggestion is provided without reservation, the currently available parking spot can become occupied by other cars during the time spent driving 
to the parking. Hence, it is important to suggest parking which has a high possibility of availability when the driver arrives. To do this, the following factor is defined, which is called the degree of availability (3). This factor estimates the possibility of finding a vacant space, considering the arrival rate of the car and the currently available number of vacant parking spots. To measure the arrival rate of a car, the mean time between arrivals, MTBA, is defined as in (2) at first.

$$
\text { MTBA }=\frac{\text { sum of time spans between arrivals }}{\text { number of arrivals }} .
$$

The MTBA represents how frequently cars arrive at the parking spot. Using the MTBA, the expected number of arriving cars to each parking spot during the driving duration of the requesting car toward the parking can be estimated. Then, the degree of availability, $A$, is calculated by the following equation:

$$
A=\frac{T_{d} / \mathrm{MTBA}}{n} .
$$

In (3), $n$ indicates the number of vacant parking spots in the parking facility. As the number of vacant parking spots and the MTBA increase (i.e., a plenty of vacant parking spots exist and less cars will arrive), the value of the degree of availability decreases, which means that it is more likely to find a vacant parking spot when a driver arrives. Hence, this factor can increase the possibility of finding a vacant parking spot based on the historical usage and current status.

Since the developing system will be implemented into a megacity that covers a large area in a highly congested environment, frequent parking failures cause other problems, as well as unreliability and annoyance. A car that fails to find vacant parking needs to move to another parking spot or wait. Frequent parking failure worsens the overall performance, especially regarding the total travel distance of all requesting cars. If there are other available parking spots near the guided parking spot which is unavailable, the requesting car can find another parking spot with a short additional driving distance. Unlike our previous work (Shin and Jun 2014), in this paper a new factor is introduced in the utility function. To reduce redundant driving distance caused by parking failure, regional possibility, $S_{p}$, to find vacant parking spots nearly is defined as (4). By this equation, the possibility of finding the next vacant parking spot nearby can be improved, so that unnecessary long distance driving to another parking spot can be eliminated.

$$
S_{p}=\sum\left(D_{p} \times A\right)
$$

In (4), $D_{p}$ represents the distance between the considered parking and the surrounding parking. For each surrounding parking place, the distance is multiplied by the degree of availability, and the calculated value is summed with all surrounding parking spots. The considered parking with a low value of regional possibility has a high possibility of finding the next vacant parking nearby. Considering all the factors affecting a parking choice without a reservation, the utility function for suggestion is defined as the following equation.

$$
\begin{aligned}
U_{s} & \left(T_{d}^{\prime}, D_{w}, P, C, A, S_{p}\right) \\
& =\beta_{1} T_{d}+\beta_{2} D_{w}+\beta_{3} P+\beta_{4} C+\beta_{5} A+\beta_{6} S_{p},
\end{aligned}
$$

where

$U_{s}$ is the utility function for suggestion,

$T_{d}^{\prime}$ is the driving distance from current location of car to parking spot,

$D_{w}$ is the walking distance from parking spot to destination,

$P$ is the parking cost,

$C$ is the traffic congestion by guidance itself,

$A$ is the degree of availability,

$S_{p}$ is the regional possibility,

$\beta$ is the weights of each factor.

Using (5), the utility of each parking spot to be suggested without reservation is calculated and compared with each other. The parking spot having the lowest value is selected and suggested to the drivers as the best parking.

4.2. Procedure for Parking Guidance. Parking guidance is conducted by the following steps.

Step 0 (Collect Parking Spot Status and Parking Information). The status change and related data of each parking spot of parking buildings, street parking, and private parking are stored and traced within the database of the central server.

Step 1 (Trigger Parking Guidance). Parking guidance is triggered by the driver's request through the personal navigation device. In the personal navigation device, a software module with a user interface to handle the driver's request is installed, and the driver can push a button to request parking guidance. After initiating the parking guidance, the destination, weight of each factor, and expected parking period should be inputted together by the driver. Then, the current location is obtained by GPS and the inputted data is transferred to the central server.

Step 2 (Find Available Parking). When the central server receives the parking guidance request, it searches the available parking spots near the destination from the stored database. This searching is done by considering the parking location from the destination, available hours of private parking, and current occupation status.

Step 3 (Return Available Parking). The found parking in the second step is sent back to the personal navigation device. The GPS location of each parking spot, current occupation status, and related parking information that is required to calculate the utility function is also transferred to the personal navigation device. 


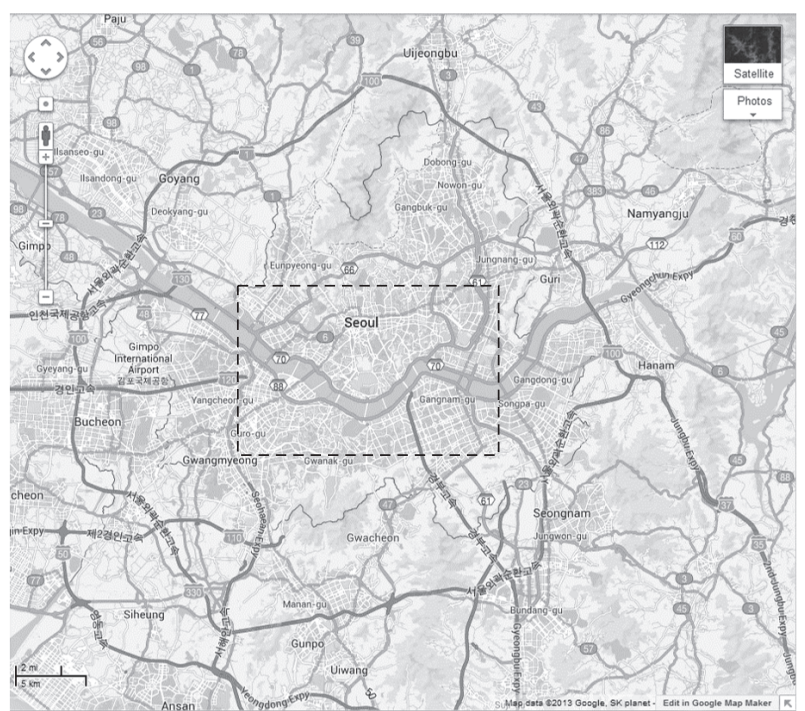

FIGURE 3: The downtown area of a big city used in the simulation experiment.

Step 4 (Calculate Utility Function for Reservation). To find the best parking for reservation, the utility function for reservation is calculated using the transferred data from the central server by (1). The calculated values of parking are sorted and the spot with the lowest value is provided to the driver on the screen of the personal navigation device. The driver can decide whether he/she reserves the provided parking or not. In the case that the reservation is requested, the reservation request is sent to the central server and the parking spot is reserved until the driver arrives.

Step 5 (Calculate Utility Function for Suggestion). In the case that the driver does not want to use the reservation option, the utility function for suggestion is calculated using (5). Like Step 4, the parking spot with the lowest value is suggested as the best parking for the driver and displayed on the screen of the personal navigation device.

Step 6 (Update Parking Spot Status). As soon as the guided car succeeds in parking, the parking spot status is changed. The monitoring sensor checks parking spot status and updates the current status to the central server. If the driver fails to park, he/she can request further parking guidance.

\section{Simulation Experiment}

This study has performed a simulation-based experiment to verify the proposed methodology and evaluates its effectiveness. The simulation has been coded and performed by MATLAB.

5.1. Simulation Setup and Assumptions. For the simulationbased experiment, the following city is targeted: around 10 million people with 7 million registered cars are living in this city (see Figure 3), and another 10 million with 4 million registered cars are within a $50 \mathrm{~km}$ distance from the city; $24 \%$ of more than 3.1 million daily commuters use their cars; the number of registered private cars is up to 2.4 million; there are about 270,000 available parking spaces; the average parking fee in the downtown area is about 5 US dollars per hour; the dotted area on the map of Figure 3 indicates the downtown of the city that covers a central area of $20.84 \mathrm{~km} \times 11.4 \mathrm{~km}$ of the entire rectangular city area $(47.2 \mathrm{~km} \times 36.5 \mathrm{~km})$; and the primary destinations of drivers and all parking are assumed to be located only in the downtown area, while parking guidance requests occur randomly throughout the entire map area. For a realistic simulation, we have set multiple parking guidance requests to occur at the same time, and the availability of parking spots in the city to change in every simulation.

To rank-order the parking facilities and find the best one using the utility function, it is required to estimate the driving distance and duration from the location where the driver requests parking guidance to parking facilities and from parking facilities to his/her destination. Note that in a real PGIS system, the distance and the duration can be calculated by the GPS navigation software in a personal navigation device. In the simulation, however, it is time consuming to calculate the exact driving distance and duration for every parking guidance request. Hence, the driving/walking distance and duration are estimated statistically, based on the sample data. To do this, 200 pairs of GPS locations are randomly generated and the straight distances between all the pairs are calculated. The real driving/walking distances between all the pairs of GPS locations are calculated by GPS navigation software. The differences between the straight distance and real driving/walking distance of all the pairs are calculated and the probability distribution of these differences is developed. The estimation of driving/walking distance from the straight distance of a pair of GPS location is done by adding a random generation based on the probability distribution to the straight distance. The driving/walking duration is estimated by the linear regression model, formulated using the driving/walking distances and their driving/walking durations by GPS navigation software.

5.2. Performance Measurement of the Proposed Parking Guidance Methodology. The performance of the proposed parking guidance methodology is evaluated with respect to the following six performance criteria:

(i) Average Driving Distance. This criterion represents the averaged driving distance per car from the initial positions of the cars to the guided parking facilities. The average driving distance could be estimated by letting the total driving distances of all cars divided by the number of cars. The lower value of this measure is preferable from the viewpoint of reducing energy waste, pollution, and other harmful effects.

(ii) Average Walking Distance. The average walking distance is equal to the total walking distance of all the drivers from the arrived parking facilities to their destinations divided by the number of drivers.

(iii) Average Level of Congestion. The traffic congestion caused by the parking guidance itself is assessed by this measure. As more cars are heading to the same 
parking facility, the traffic near the parking facility will be congested. Hence, it is more desirable to disperse cars to different parking facilities. To measure the average level of congestion per parking spot, the distribution of cars heading to each parking is calculated at each simulation time and the mean of all distributions during a simulation period is defined as the average level of congestion. The lower level of this measure indicates that cars are evenly assigned to each parking spot, which can reduce traffic congestion.

(iv) Average Occupancy Rate of Parking Spots. From the viewpoint of the utilization of parking resources, it is beneficial to increase the occupancy rate of all available parking spots in the city. The occupancy rate is defined as the ratio of parking spots occupied during the simulation versus the total number of parking spots in the city.

(v) Average Parking Failure Rate. The recommended parking facility may happen to be fully occupied when a driver arrives there. As the number of drivers who get parking guidance support but fail to find vacant parking space increases, the levels of satisfaction of and reliability for drivers decrease. Moreover, parking failure causes additional driving to another parking spot, and eventually, drivers may no longer want to use the proposed system. To prevent this, it is important to measure and reduce the parking failure rate. The level of parking failure is calculated by the sum of all parking failures divided by the number of all parking facilities and by the simulation period.

(vi) Average Requesting Number. In some cases, it is difficult to find available parking spots. The car which fails to find a vacant parking spot needs to find another parking and request parking guidance again. This measure shows how many times a driver requests parking guidance, on average, until he/she succeeds to park. The requesting number of all cars is summed and divided by the number of cars. To prevent driver's frustration, the average requesting number should be reduced.

5.3. Simulation Parameters. The performance measures can be affected by the setting of the weight of each factor in the utility function. Hence, it is important to decide how much weight is given to each factor. In this experiment, the authors assume two preference types: (1) weights of factors are decided by each driver (more individual preference) and (2) weights of factors are decided by the central server (central control). In both different preference types, the weight of each factor is decided manually by humans so that the simplified preference levels, such as low (1), medium (2), and high (3), are used in the simulation. The predefined preference types of weight factors in the case of central control and their meanings are described in Table 1. To compare the performance improvement, the preference named "base preference" is defined, and this assumes that all cars are heading to the nearest public parking to their destinations in a straightforward way, without the help of any parking guidance system.

To check the effectiveness of the proposed parking guidance methodology, different experiments according to parking request demands and parking resources supply are tested (see Table 2). "Experiment I" focuses on the effect of variations of the parking request demands. To change the demand level, the maximum number of parking requesting cars $(N)$ per simulation time is set to three levels $(N=$ 500,1000 , and 2000 cars). The parking request is generated as a uniform random distribution between zero and the maximum number of parking requesting cars $(N)$ at each simulation time, so that the number " $N$ " regulates the level of parking request demands. To vary parking supply and study its effect, "Experiment II" was designed. In "Experiment II," parking supply is defined as three degrees according to the number of available parking spots, location congestion of parking, and initial occupation status of parking facilities. The first case assumes a congested situation, so the initial occupancy rate of parking facilities is set to a high level in the range of $80 \sim 100 \%$, which represents a parking supply shortage. To maximize the congestion effect and check how the downtown area affects performance measures, the area of downtown is squeezed compared to other cases. The second case has the same area as the first case of "Experiment I" but is highly occupied at the beginning of the simulation to reduce parking supply. The last one doubles the supply of public parking and private parking, which means that the parking supply is expanded.

In the simulation, the data related to a parking facility (i.e., location, cost, capacity, and initial occupation rate) is randomly generated according to the parameter values (see Table 2). The total simulation period is defined as 240 units of time in order to reduce the calculation burden. To consider cars not using the proposed system on the road, the unexpected occupation of public parking spots by these cars is defined as a random number between zero and three cars per simulation time. The number of freed parking spots per parking facility is also randomly generated in the same way as the unexpected occupation. Since the target city is too big to consider all parking areas, and it is meaningless to consider parking far away from the destination, the searching area to find parking is confined to a $2 \mathrm{~km}$ radius. Regarding the driver's behavior, the reservation acceptance probability is defined as $50 \%$, which means that there is a $50 \%$ probability that a driver will accept the reservation option. When a driver fails to find a vacant parking spot with the guided parking, the driver can either request further parking guidance or give up using parking guidance. This is defined as the rerequesting probability and it is set to $80 \%$, which means that there is about an $80 \%$ probability a driver will request further parking guidance. Table 2 summarizes the setting value of simulation parameters.

5.4. Results and Analysis. Table 3 shows the result of "Experiment I."

As explained, the base preference chooses the nearest parking to the destination without any guidance, so no private parking is used in this case. Without the help of the parking 


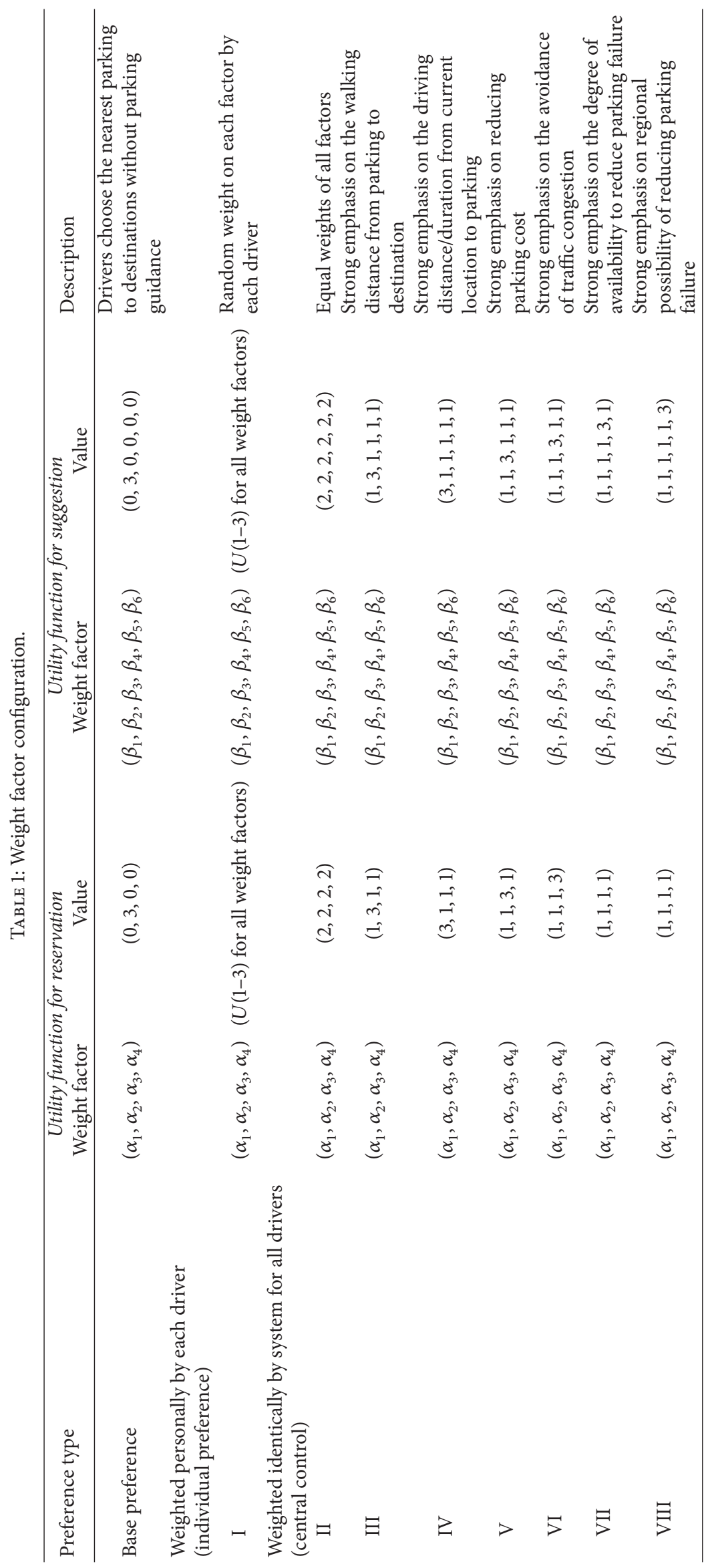




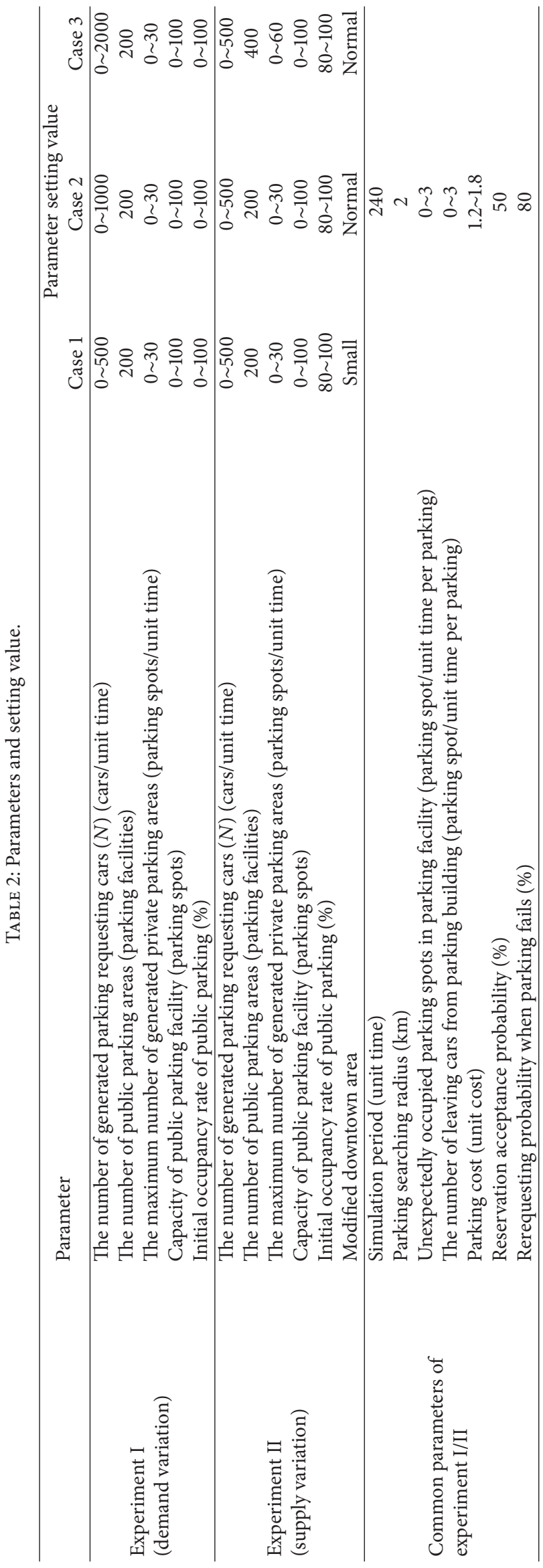




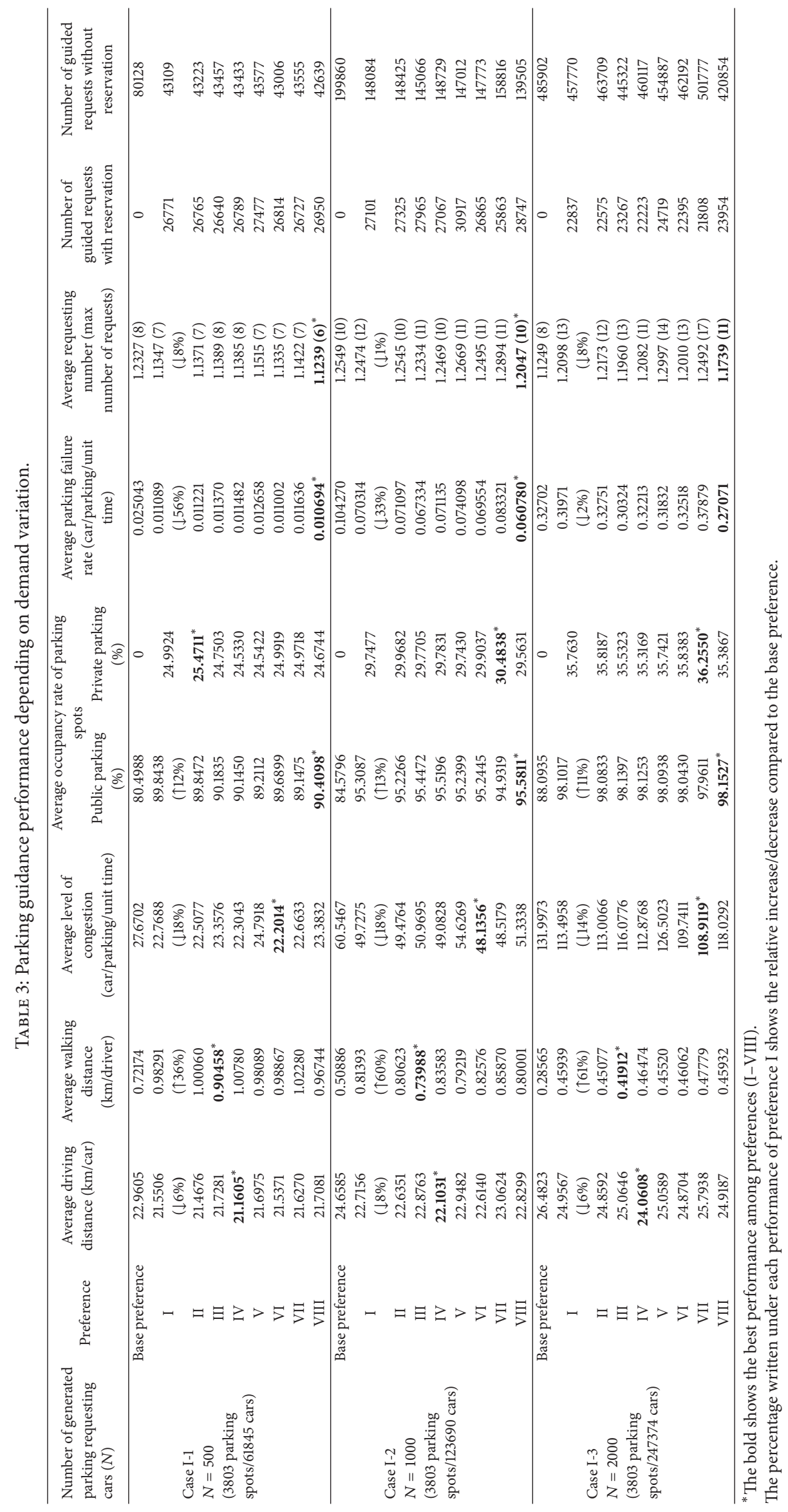




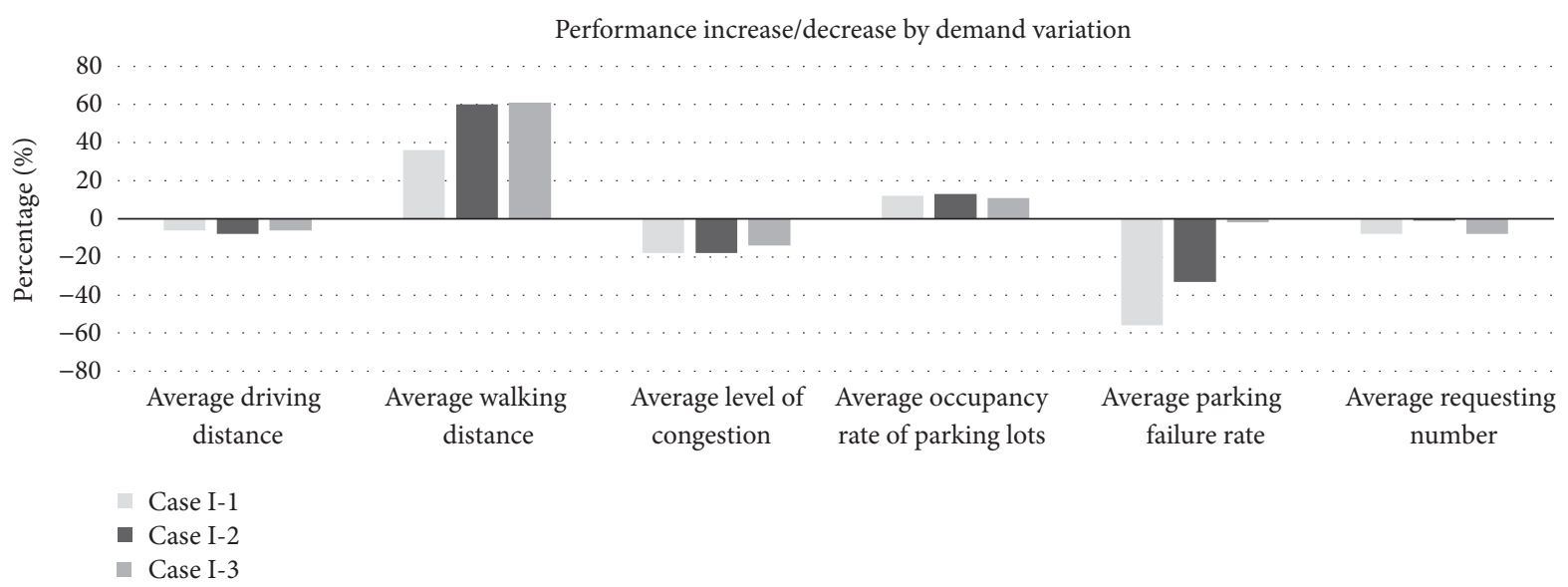

FIgURE 4: Performance increase and decrease by demand variation.

guidance system, it is difficult for a driver to find private parking which is dynamically available. The reservation under the base preference is also impossible without the parking guidance system, so there is no trial record of reservations, as shown in the 10th column (number of guided requests with reservation) of Table 3 . Due to its characteristics of parking choice, the base preference shows the best performance of the average walking distance compared to other preferences. However, other performance measures of the base preference show worse results than those of other preferences, which means that the applications of the proposed methodology can be a possible solution to the parking problem.

As described in Table 1, preference I puts arbitrary weights on each factor by each driver, and all of the performance measures, except the average walking distance and average requesting number for all cases in "Experiment I," show a better performance than those of the base preference, regardless of parking request demand variation. Even though the average walking distance increases, the additional distance for drivers to walk does not exceed $300 \mathrm{~m}$ on average, which seems not to be critical hindrance to use the guided parking. It is assumed in preferences II-VIII that the weight of each factor is configured by the central server identically for all drivers.

Since the important balance among weights of factors can be adjusted depending on the objective of a parking guidance policy, the authors define several types of preferences, as shown in Table 1 (see preferences II-VIII). In most preferences II-VIII, the total travel distance that includes both driving distance and walking distance becomes less than that of the base preference. For example, by using the intelligent parking guidance, about $600,000 \mathrm{~km}$ of driving distance (i.e., the case I-3) can be reduced totally, which means that a huge amount of energy can be saved. Preference IV shows quite good performance on the average driving distance, since the highest weight is put on the factor related to driving distance and duration. The parking spot with a shorter driving distance and less duration from a requesting car has the higher priority than other available parking spots in this preference. Hence, it is likely that the closer parking spot from the current location of the car is selected and provided to drivers. Preference II puts more emphasis on walking distance, so this preference shows a good performance of the average walking distance. However, unlike the base preference, the nearest parking spot from the destination is not always selected, since the proposed methodology considers other factors concurrently in the assessment. Therefore, even though the strongest emphasis is given to the factor related to walking distance, the average walking distance of preference II cannot beat that of the base preference.

Regarding the average level of congestion, preference VI shows a good performance since the number of cars heading to each parking spot is more emphasized in this preference. A parking spot with high congestion is strongly avoided so that the average level of congestion can be reduced. From the viewpoint of parking management of a city, it is important to maximize the utilization of spatial resources. The average occupancy rate of parking spots indicates how well the parking spot is utilized. Since there is no factor directly related to utilization, it seems that there is no dominant preference for utilization increase. However, it seems that the factor "regional possibility" has a tendency to improve the parking utilization. According to the last two columns in Table 3, the number of guided cars using reservations does not increase much, contrary to the expanding guidance by suggestion. It is because the number of parking spots is confined, so the expansion of available parking spots for reservation is limited. The number of reservation options seems to be dependent on the number of available parking spots. To provide more opportunities for reservations, an increase of available parking spots will be helpful.

Figure 4 shows the increase or decrease of performance measures compared to those of the base preference according to demand variation. According to Figure 4, three performance measures (average driving distance, average level of congestion, and average occupancy rate of parking spots) show little improvement over those of the base preference. On the contrary, the improvement of the averaged parking failure rate dramatically worsens as the demand $(N)$ increases. 


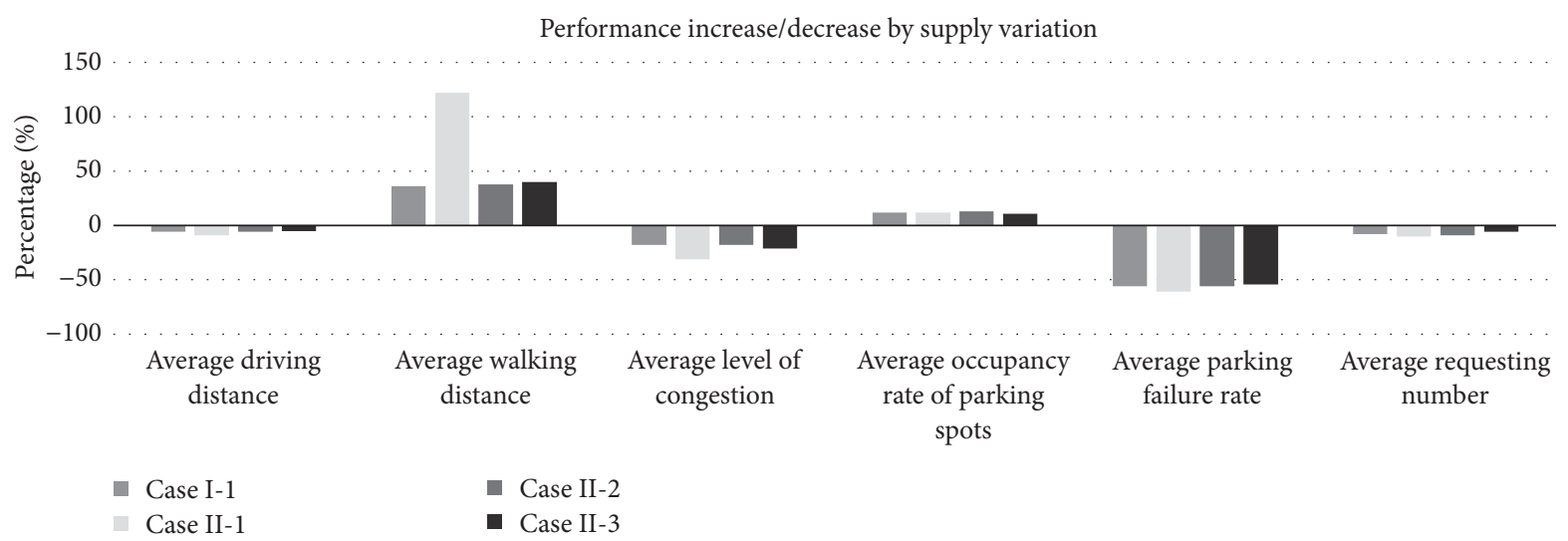

FIGURE 5: Performance increase and decrease by supply variation.

As shown in the column of public parking utilization, the number of vacant parking spaces decreases as the demand $(N)$ increases, so the effect of guidance to reduce parking failure is diminishing. In the case of another performance measure, the averaged walking distance also worsens (larger) as the demand $(N)$ increases. Like the average parking failure rate, the increased number of demands $(N)$ makes it difficult for a driver to find a vacant parking spot near the destination, so drivers must walk further to get to their destinations.

The result of "Experiment II" is described in Table 4.

As shown in Table 4, similar to the result of "Experiment I," the performance measures of all preferences (I-VIII), except the average walking distance, show better results than those of the base preference. This means that the proposed parking guidance methodology is also effective regardless of supply variation within the simulation. The best scored performance measure by preferences is similar to "Experiment I." However, the average parking failure rate in case II-1 shows the best performance with preference VI, which indicates that the regional factor does not have much impact on reducing parking failure in the case of the squeezed downtown area. The factor "regional possibility" seems to be effective on the large area, so it is expected to be used in reducing parking failure in a megacity environment. On the other hand, the average level of congestion and average parking failure rate are improved quite a lot compared to those of the base preference. Preferences III and IV are designed to improve the averaged driving distance and the averaged walking distance, so the best performances are scored by these preferences. However, unlike "Experiment I," preference VI does not always guarantee the best performance of the average level of congestion. In the case that there are many available vacant parking spots, the factor for traffic congestion cannot dominate other factors. Therefore, the traffic congestion of case II-3 scores the best performance with preference IV.

The performance increase and decrease compared to the base preference depending on supply variation are depicted in Figure 5. This increase or decrease of performance measures compared to the base preference seems to not be much affected by supply variation, since there is no factor considering supply directly.
Regarding two preference types (individual and central), the best performance of each measure is obtained by the centrally controlled parking guidance, depending on the preferences. However, other performance measures are sacrificed for the best measure on each preference. Figure 6 depicts how much the performance of individual preference differs from the best performance obtained from central control (preferences II-VIII). According to Figure 6, the performance increase/decrease does not exceed $20 \%$, except the average walking distance of case I-2. Even though the individually defined preference on parking choice factors does not score the best performance, it is better than the base preference, so the proposed methodology will be beneficial to parking management of city.

To prove the effectiveness of the proposed methodology, the statistical analysis is carried out using two sample $t$-tests with the level of significance at $5 \%$. The performance measures of preference I are compared with those of the base preference. In total, 30 different sets of the first case of "Experiment I" are generated and tested. The analysis result of the $t$-test is described in Table 5 and shows that the performance measures, except the averaged walking distance, are improved compared to those of the base preference. All the $P$ values of the performance measures are less than 0.05 , which means that the improvement of performance measures, except the averaged walking distance, is accepted statistically.

The proposed methodology includes private parking in the parking management of a city. To analyze the utilization of private parking, Figure 7 is plotted. The used data in this figure is the first case of "Experiment I."

In Figure $7(\mathrm{a})$, the black line represents the available period of private parking and the gray line is the occupied period. According to the simulation test, the utilization of private parking is lower than that of public parking. Since the parking spot is selected by the utility function, the normalized mean value of each factor in the utility function during simulation is calculated and drawn in Figures 7(b) and 7(c) for public parking and private parking, respectively. In Figures 7 (b) and 7(c), the overall utility of private parking is lower than that of public parking, which means that private parking 


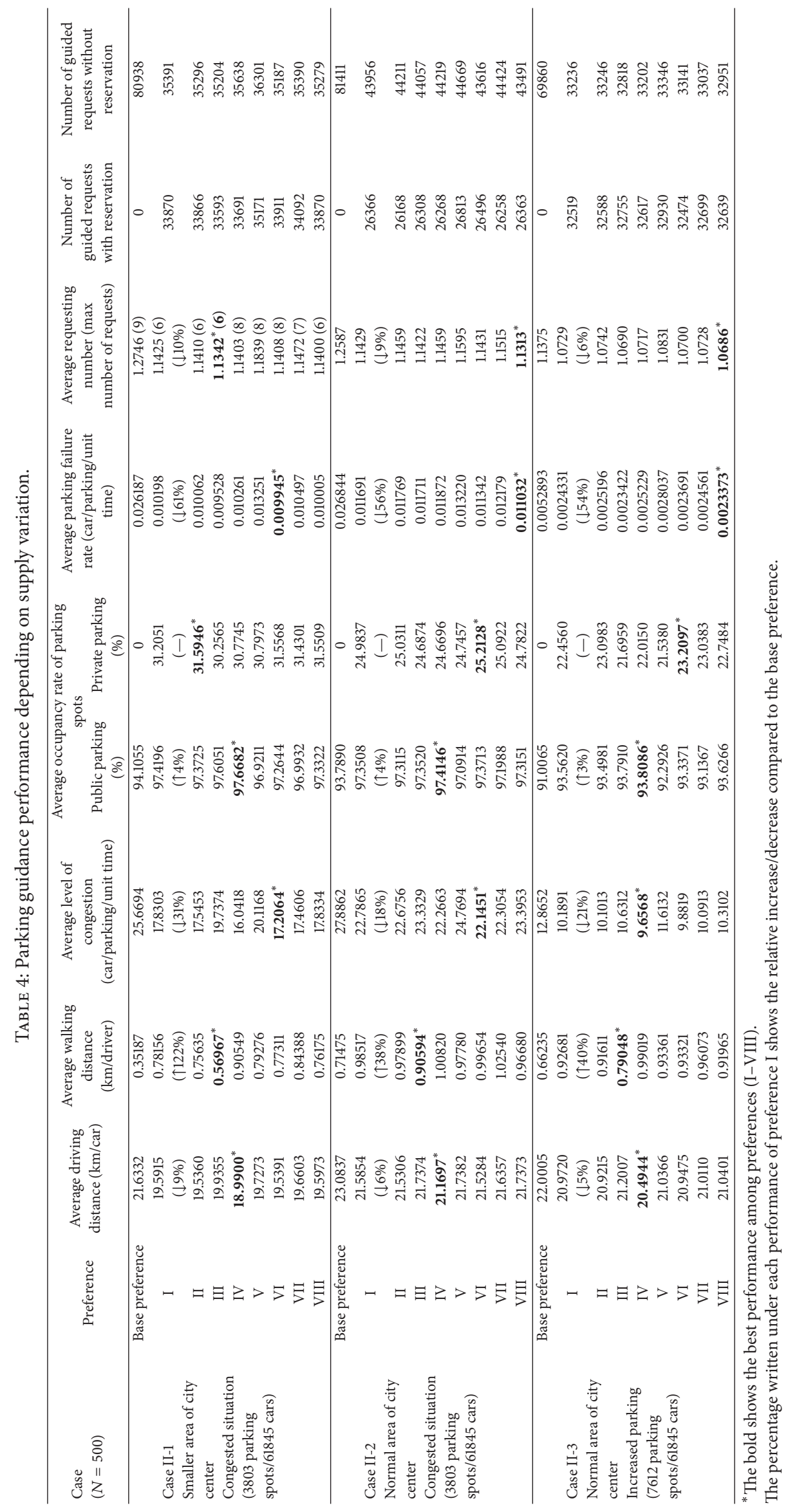


Performance comparison (individual versus central)

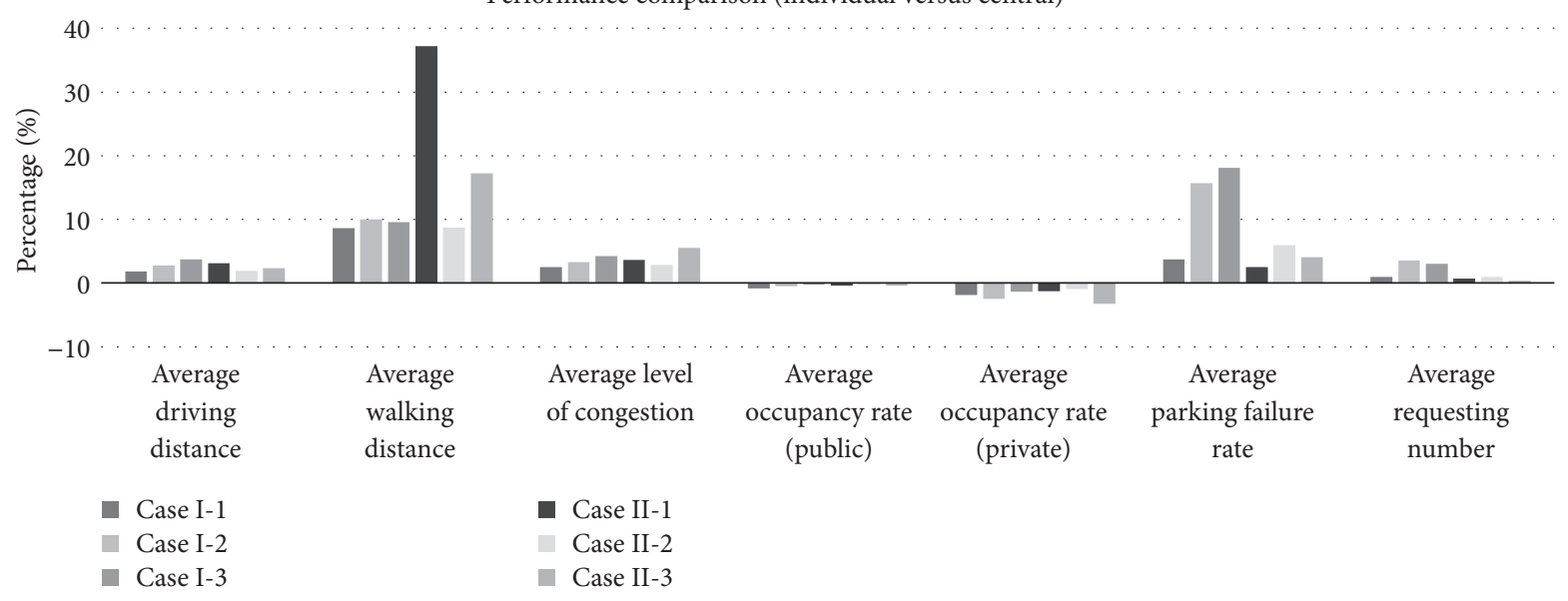

FIGURE 6: Performance increase and decrease by supply variation.

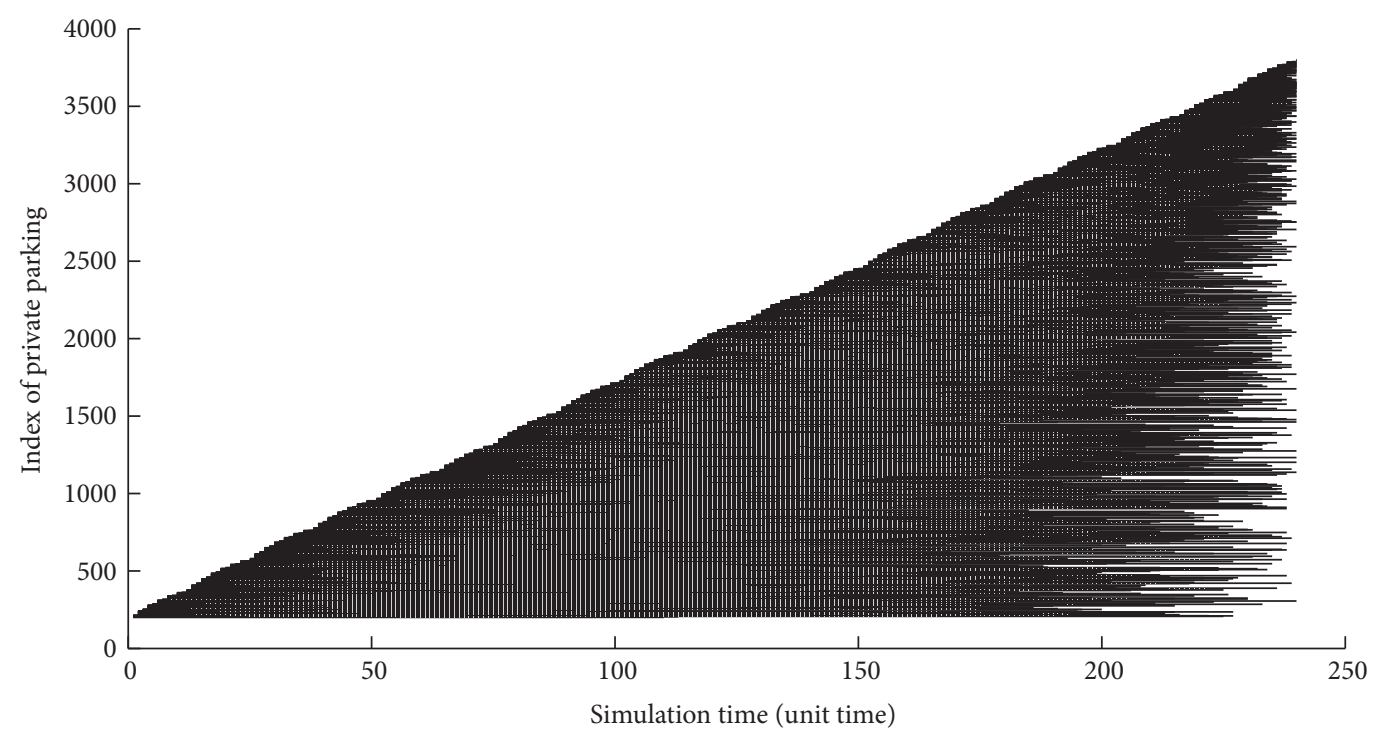

(a) Occupancy status of private parking

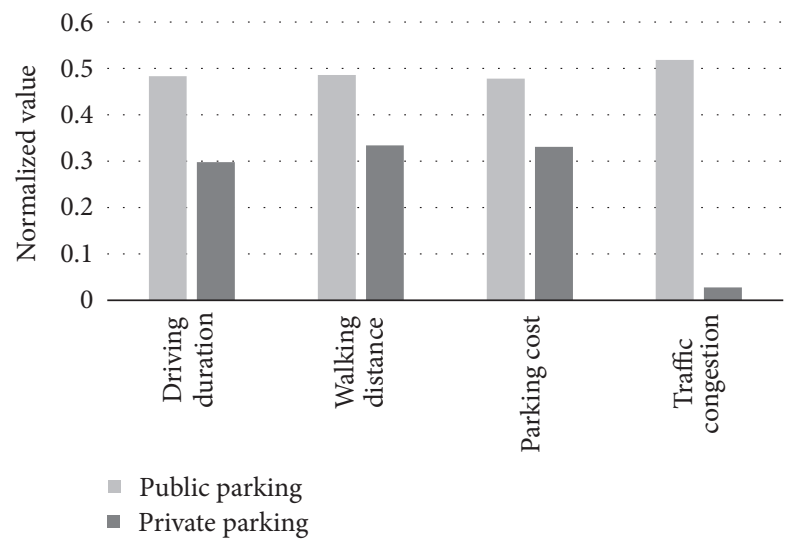

(b) Mean of each factor of the utility function for reservation

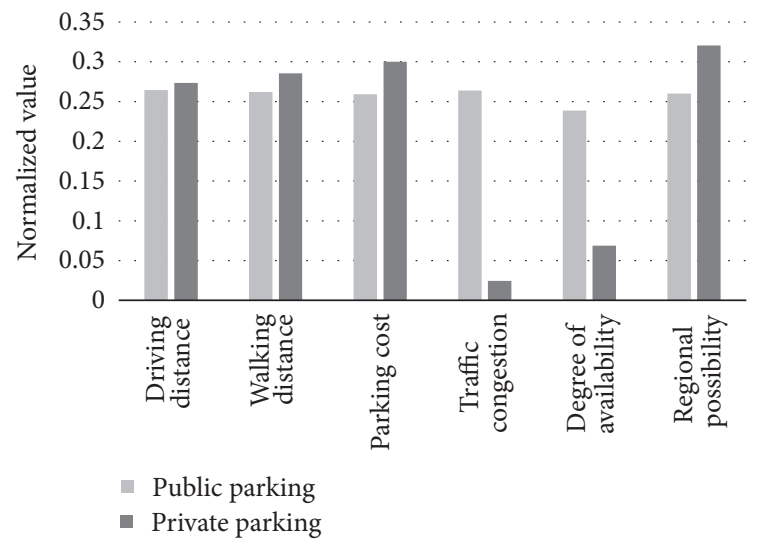

(c) Mean of each factor of the utility function for suggestion

FIgURE 7: Utilization of private parking. 
TABLE 5: Two-sample $t$-test.

\begin{tabular}{lccccccc}
\hline & $\begin{array}{c}\text { Averaged } \\
\text { driving distance } \\
(\mathrm{km})\end{array}$ & $\begin{array}{c}\text { Averaged } \\
\text { walking distance } \\
(\mathrm{km})\end{array}$ & $\begin{array}{c}\text { Averaged } \\
\text { congestion (car) }\end{array}$ & $\begin{array}{c}\text { Averaged parking } \\
\text { utilization } \\
\text { Public } \\
\text { parking (\%) }\end{array}$ & $\begin{array}{c}\text { Private } \\
\text { parking }(\%)\end{array}$ & $\begin{array}{c}\text { Averaged } \\
\text { failed car } \\
(\text { car })\end{array}$ & $\begin{array}{c}\text { Averaged requesting } \\
\text { number (max } \\
\text { number of requests) }\end{array}$ \\
\hline $\begin{array}{l}\text { Base preference } \\
\quad \text { Mean }\end{array}$ & 22.5005 & 0.6512 & 25.5778 & 76.7635 & $(-)$ & 0.0193 & $1.1604(6.3226)$ \\
$\quad \begin{array}{l}\text { Standard deviation } \\
\text { Preference I }\end{array}$ & 0.0443 & 0.0103 & 0.5546 & 1.1304 & $(-)$ & 0.0007 & $0.0043(0.5408)$ \\
$\quad$ Mean & & & & & & & \\
$\quad$ Standard deviation & 0.0259 & 0.0155 & 0.3149 & 0.8406 & 0.3575 & 0.0004 & $0.0032(1.0905)$ \\
$T$ & 118.109 & -76.0936 & 38.846 & -41.4975 & $(-)$ & 64.8038 & $46.4647(-5.6069)$ \\
$P$ & $9.196 E-73$ & $2.2006 E-61$ & $3.1263 E-44$ & $6.8432 E-46$ & $(-)$ & $3.00 E-57$ & $\begin{array}{c}9.4806 E-49 \\
(5.51 E-07)\end{array}$ \\
\hline
\end{tabular}

has a higher chance to be selected for reservation. However, public parking is more frequently provided in spite of its worse utility. This is because the available period of private parking restricts its selection. To increase the utilization of private parking, it seems desirable to put an advantage to the private parking which has a matched available period.

From the simulation test, it is verified that the proposed methodology improves both a driver's benefits and parking management of a city from various points of view. Compared to the conventional way for drivers to choose parking, the proposed methodology reduces driving distance from current car location to parking, relieves traffic congestion by guidance itself, increases utilization of parking resources including both public and private, and provides convenience to secure a parking space by reservation. Moreover, the proposed methodology makes it possible for private parking to participate in the parking management of a city and to respond to dynamic parking demands.

\section{Conclusion and Discussion}

In this paper, we have proposed a novel intelligent parking guidance methodology for a megacity, which includes both public parking facilities and private parking. To assess and select the best parking, two kinds of parking utility functions are formulated and used. The first parking utility function is designed to provide reservation options to secure a parking spot until the driver arrives at the guided parking. This utility function focuses on the cost perspective factors that are required to preserve a parking spot as vacant. Hence, the temporal and monetary cost factors, such as driving duration and parking cost, are included in this utility function. The other function aims to provide the best parking space without a reservation. Since there is no guarantee for vacant parking when the driver arrives, this utility function considers the possibility of finding an empty parking space so that two factors, such as the degree of availability and the regional possibility, are defined and included. Other factors affecting parking choice behavior are also included in both utility functions so as to enhance the driver's satisfaction and the public benefits. In addition, the defined utility functions are also designed to avoid traffic congestion caused by guidance itself. Unlike conventional parking guidance, the proposed methodology is designed to consider private parking as an available parking resource, as well as public parking facilities. During the simulation, private parking is dynamically joined in the parking management of a city and successfully provided to drivers. In spite of the effectiveness of the utility functions to assess and select parking, to decide a proper amount of weight for each factor still remains as a problem. An optimal weight configuration can be varied depending on the parking environment and operation strategy of the system. A proper methodology to find optimal weight configuration needs to be studied in the future.

The proposed methodology is tested using a computational simulation so as to verify the proposed system and analyze its effectiveness using an exemplary case of the megacity. Depending on the results of the simulation test, the proposed methodology proves its usefulness. Compared to the straightforward parking choice generally conducted by most drivers, most of the performance measures are significantly improved. The driving distance to parking and the traffic congestion by guidance become diminished. Moreover, the parking failure rate is also reduced when using the proposed methodology. From the viewpoint of the city, the utilization of parking resources increases quite a lot. While the walking distance in the proposed methodology is increased over the conventional parking method, this increase seems to be negligible considering the benefits of the other performance measures. In addition, two kinds of management policies (individual preference and central control) are studied by the simulation, and it is shown that the centrally controlled parking has the best performance at the cost of other performance measures. However, individual preference scores better than the base preference, which proves both parking guidance policies can be beneficial to the parking management of a city.

In spite of the verification of the usefulness of the proposed methodology, there still remain many challenging issues on further research and implementation. First, it is needed to reduce repeated parking failure of a driver. According to the simulation test, some cars are analyzed to 
fail to find vacant parking spot repeatedly whenever they arrive at the guided parking. Too many parking failures for a driver will degrade the reliability of the proposed system, which may hinder drivers from using the presented smart parking guidance system. Second, the utilization of private parking keeps low level, which may make the owners of private parking hesitate to participate in the parking management of a city. To maximize the spatial resources, more private parking is desirable and the utilization of it should be increased. To do this, a new factor or procedure to give the higher priority on private parking can be considered. In this study, the effectiveness of using utility function is well described, but it is still needed to modify many parameters according to real parking environment. These issues should be studied and improved in future work, for developing better parking guidance systems with accompanying management policies. Third, in the studied developing system, the parking selection is performed by the information that is collected at the moment of parking guidance request. Hence, each requesting car uses the different information which changes as time goes. Due to this characteristic, the suggested parking spot cannot be altered even though the information changes. To cover this limitation, all the requesting cars in the megacity should be traced and the selected parking is reassessed continuously, which is impossible due to computational time and cost. Hence, the available solution to this limitation is that the reassessment of parking selection should be performed discretely during driving to parking spot. However, the decision of reassessment interval or policy needs more study and this will be the further research work.

\section{Conflicts of Interest}

The authors declare that there are no conflicts of interest regarding the publication of this paper.

\section{Acknowledgments}

This study was supported by research fund from Chosun University, 2016.

\section{References}

[1] Y. S. Cheung, S. Coleri, and P. Varaiya, "Traffic surveillance with wireless magnetic sensors," in Proceedings of the 12th ITS World Congress, San Francisco, Calif, USA, 2005.

[2] H. Ichihashi, A. Notsu, K. Honda, T. Katada, and M. Fujiyoshi, "Vacant parking space detector for outdoor parking lot by using surveillance camera and FCM classifier," in Proceedings of the IEEE International Conference on Fuzzy Systems, pp. 127-134, Jeju Island, South Korea, August 2009.

[3] Z. Pala and N. Inanç, "Smart parking applications using RFID technology," in Proceedings of the 1st Annual RFID Eurasia, Istanbul, Turkey, September 2007.

[4] M. Y. I. Idris, E. M. Tamil, N. M. Noor, Z. Razak, and K. W. Fong, "Parking guidance system utilizing wireless sensor network and ultrasonic sensor," Information Technology Journal, vol. 8, no. 2, pp. 138-146, 2009.
[5] S. Lee, D. Yoon, and A. Ghosh, "Intelligent parking lot application using wireless sensor networks," in Proceedings of the International Symposium on Collaborative Technologies and Systems (CTS '08), pp. 48-57, Irvine, Calif, USA, May 2008.

[6] V. W. S. Tang, Y. Zheng, and J. Cao, "An intelligent car park management system based on wireless sensor networks," in Proceedings of the SPCA 2006: 1st International Symposium on Pervasive Computing and Applications, pp. 65-70, Urumqi, China, August 2006.

[7] J. Chinrungrueng, U. Sunantachaikul, and S. Triamlumlerd, "Smart parking: an application of optical wireless sensor network," in Proceedings of the International Symposium on Applications and the Internet-Workshops, SAINT-W, Hiroshima, Japan, January 2007.

[8] S.-E. Yoo, P. K. Chong, T. Kim et al., "PGS: parking guidance system based on wireless sensor network," in Proceedings of the 3rd International Symposium on Wireless Pervasive Computing (ISWPC '08), pp. 218-222, Santorini, Greece, May 2008.

[9] S. M. Shin, S. W. Park, and S. H. Hong, "Parking management system using ZigBee," International Journal of Computer Science and Network Security, vol. 6, no. 7, pp. 131-137, 2006.

[10] V. K. Boda, A. Nasipuri, and I. Howitt, "Design considerations for a wireless sensor network for locating parking spaces," in Proceedings of the IEEE SoutheastCon, pp. 698-703, Richmond, Va, USA, March 2007.

[11] S. V. Srikanth, P. J. Pramod, K. P. Dileep, S. Tapas, M. U. Patil, and S. C. Babu N, "Design and implementation of a prototype smart parking (SPARK) system using wireless sensor networks," in Proceedings of the International Conference on Advanced Information Networking and Applications Workshops (WAINA '09), pp. 401-406, Bradford, UK, May 2009.

[12] D. Silva, P. Bartolomeu, and J. Fonseca, "Wireless parking lot monitoring and guidance," in Proceedings of the IEEE 16th Conference on Emerging Technologies and Factory Automation (ETFA '11), Toulouse, France, September 2011.

[13] M. Caliskan, A. Barthels, B. Scheuermann, and M. Mauve, "Predicting parking lot occupancy in vehicular ad hoc networks," in Proceedings of the IEEE 65th Vehicular Technology Conference (VTC’07), pp. 277-281, Dublin, Ireland, April 2007.

[14] Z. Y. Mei and Y. Tian, "Optimized combination model and algorithm of parking guidance information configuration," EURASIP Journal on Wireless Communications and Networking, vol. 2011, article 104, 2011.

[15] R. G. Thompson, K. Takada, and S. Kobayakawa, “Optimisation of parking guidance and information systems display configurations," Transportation Research Part C: Emerging Technologies, vol. 9, no. 1, pp. 69-85, 2001.

[16] R. G. Thompson and A. J. Richardson, "A parking search model," Transportation Research Part A: Policy and Practice, vol. 32, no. 3, pp. 159-170, 1998.

[17] F. Caicedo, "Real-time parking information management to reduce search time, vehicle displacement and emissions," Transportation Research Part D: Transport and Environment, vol. 15, no. 4, pp. 228-234, 2010.

[18] D. Teodorović and P. Lučić, "Intelligent parking systems," European Journal of Operational Research, vol. 175, no. 3, pp. 1666-1681, 2006.

[19] B. J. Waterson, N. B. Hounsell, and K. Chatterjee, "Quantifying the potential savings in travel time resulting from parking guidance systems-a simulation case study," Journal of the Operational Research Society, vol. 52, no. 10, pp. 1067-1077, 2001. 
[20] S.-Y. Chou, S.-W. Lin, and C.-C. Li, "Dynamic parking negotiation and guidance using an agent-based platform," Expert Systems with Applications, vol. 35, no. 3, pp. 805-817, 2008.

[21] P. Bonsall and I. Palmer, "Modelling drivers' car parking behaviour using data from a travel choice simulator," Transportation Research Part C: Emerging Technologies, vol. 12, no. 5, pp. 321-347, 2004.

[22] E. Jonkers, M. Van Noort, and J. L. Van Der Veen, "Parking guidance-modelling, simulation and impact assessment," in Proceedings of the 14th IEEE International Intelligent Transportation Systems Conference (ITSC '11), pp. 858-864, Washington, Wash, USA, October 2011.

[23] Z.-Y. Mei, Y.-Q. Xiang, J. Chen, and W. Wang, "Optimizing model of curb parking pricing based on parking choice behavior," Journal of Transportation Systems Engineering and Information Technology, vol. 10, no. 1, pp. 99-104, 2010.

[24] T. Giuffrè, S. M. Siniscalchi, and G. Tesoriere, "A novel architecture of parking management for smart cities," Procedia-Social and Behavioral Sciences, vol. 53, pp. 16-28, 2012.

[25] C. J. Rodier and S. A. Shaheen, "Transit-based smart parking: an evaluation of the San Francisco Bay area field test," Transportation Research Part C: Emerging Technologies, vol. 18, no. 2, pp. 225-233, 2010.

[26] Y. Geng and C. G. Cassandras, "A new 'smart parking' system based on optimal resource allocation and reservations," in Proceedings of the 14th IEEE International Intelligent Transportation Systems Conference (ITSC '11), pp. 979-984, Washington, Wash, USA, October 2011.

[27] E. Yourdon and L. Constantine, Structured Design, YOURDON Press, New York, NY, USA, 1975.

[28] S. An, B. Han, and J. Wang, "Study of the mode of real-time and dynamic parking guidance and information systems based on fuzzy clustering analysis," in Proceedings of the International Conference on Machine Learning and Cybernetics, pp. 27902794, Shanghai, China, August 2004.

[29] W. H. K. Lam, Z. Li, H. Huang, and S. C. Wong, "Modeling timedependent travel choice problems in road networks with multiple user classes and multiple parking facilities," Transportation Research Part B: Methodological, vol. 40, no. 5, pp. 368-395, 2006.

[30] F. Caicedo, C. Blazquez, and P. Miranda, "Prediction of parking space availability in real time," Expert Systems with Applications, vol. 39, no. 8, pp. 7281-7290, 2012.

[31] D. A. Hensher and J. King, "Parking demand and responsiveness to supply, pricing and location in the Sydney central business district," Transportation Research A: Policy and Practice, vol. 35, no. 3, pp. 177-196, 2001.

[32] J.-H. Shin and H.-B. Jun, "A study on smart parking guidance algorithm," Transportation Research Part C: Emerging Technologies, vol. 44, pp. 299-317, 2014. 


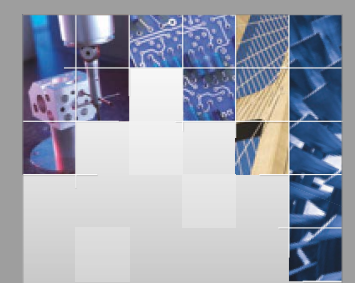

\section{Enfincering}
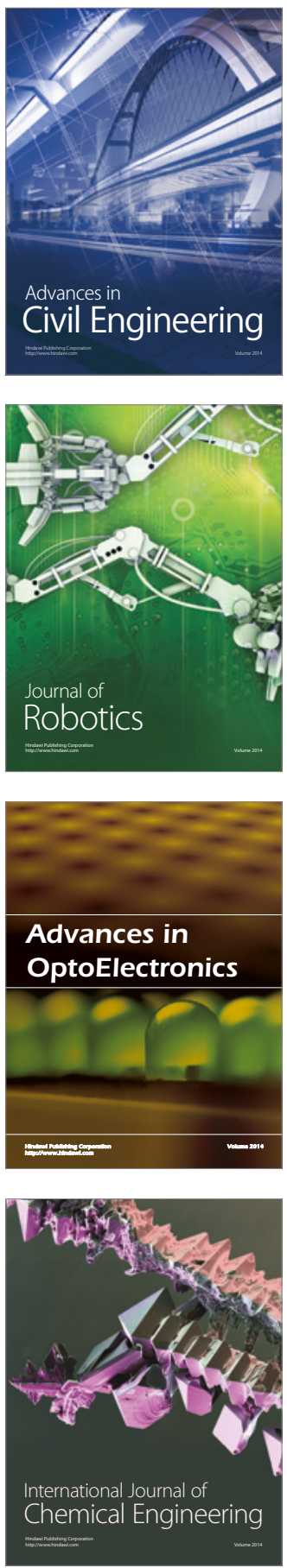

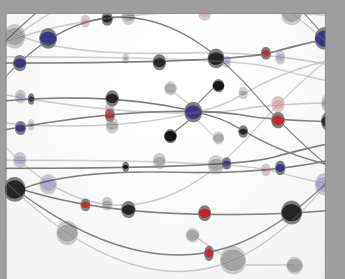

The Scientific World Journal

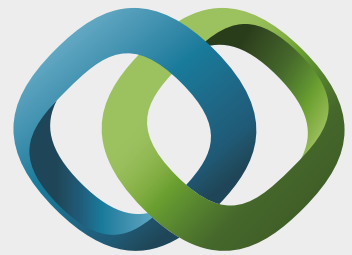

\section{Hindawi}

Submit your manuscripts at

https://www.hindawi.com
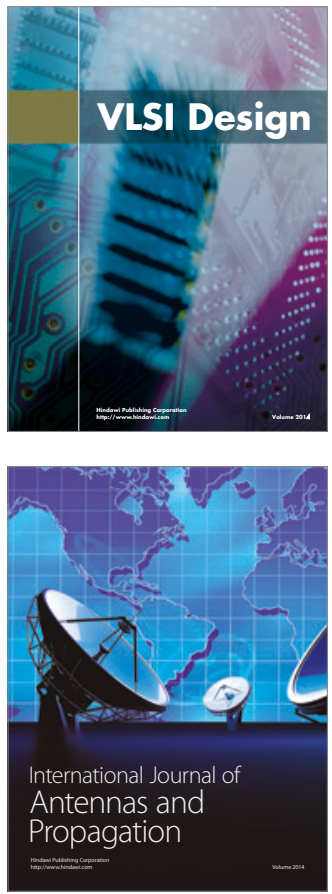

\section{Rotating}

Machinery
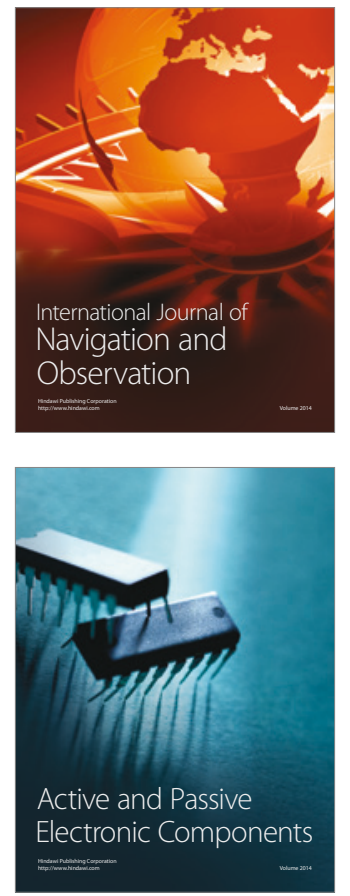
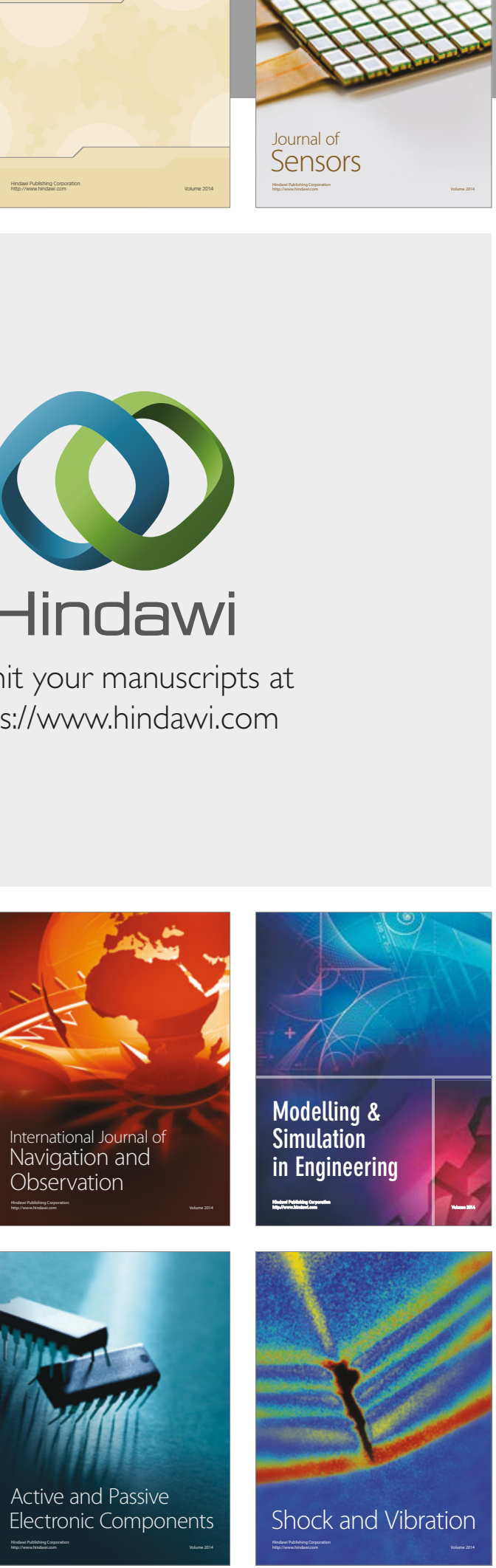
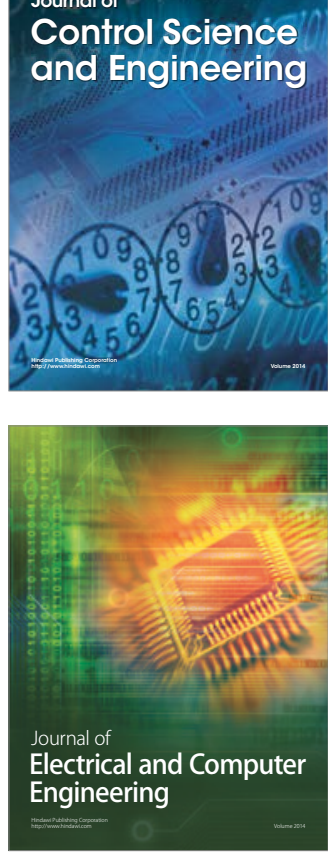

Distributed

Journal of

Control Science

and Engineering
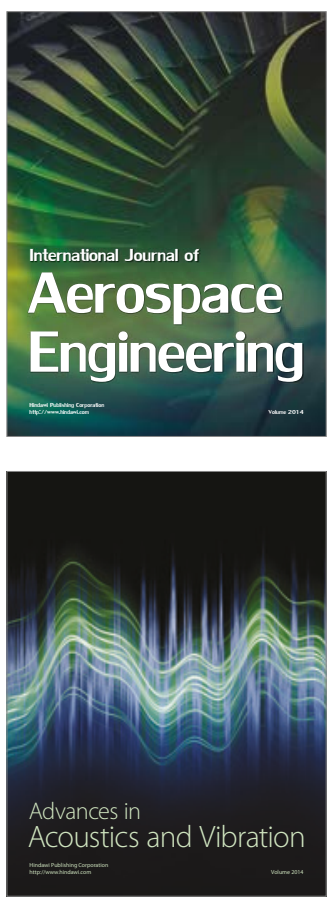

Sensor Networks 